\title{
Habitar la frontera. Una cuestión de confianza
}

Inhabiting the border. A matter of trust

\author{
Remedios Ávila Crespo \\ Catedrática de Filosofía. Universidad de Granada (España) \\ ravila@ugr.es
}

\section{ATEÍSMO, CREENCIA Y SENTIDO. HOMENAJE A JUAN ANTONIO ESTRADA MONOGRÁFICO COORDINADO POR REMEDIOS ÁVILA Y MIGUEL MORENO}

\section{RESUMEN}

Tomando como punto de partida y también de referencia las reflexiones del profesor Juan Antonio Estrada acerca de por qué es imposible una teodicea, este trabajo se propone abordar un doble problema: el problema del mal y el problema del sentido y lo hace desde una perspectiva: la pérdida de la confianza y lo que se sigue de esa pérdida. El Libro de Job, las reflexiones de Nietzsche y de A. Camus son, junto a las de Estrada, el horizonte en el que se enmarcan esas reflexiones.

\section{ABSTRACT}

Taking as a starting point and also as a reference the reflections of Professor Juan Antonio Estrada about why a theodicy is impossible, this work aims to address a double problem: the problem of evil and the problem of meaning, and it does so from a perspective: the loss of confidence and what follows from that loss. The Book of Job, the reflections of Nietzsche and A. Camus are, together with those of Estrada, the horizon in which these reflections are framed.

"Con la muerte de mi madre desapareció de mi vida toda felicidad estable, todo lo que era tranquilo y seguro. Iba a tener mucha diversión, muchos placeres, muchas ráfagas de Alegría; pero nunca más tendría la antigua seguridad. Solo habría mar e islas: el gran continente se había hundido, como la Antártida" (C. S. Lewis, Cautivado por la alegría).

\section{Introducción}

El tiempo es un gran maestro. Un maestro que enseña lo que se es y que lo hace visible en lo que se hace. El "libro de actas" de nuestra vida, que comienza con una de nacimiento y termina con otra de defunción, es un buen lugar para consultar, en el intervalo que transcurre entre el inicio y el final, lo que hacemos, es decir, lo que somos (Operari sequitur ese, decían los antiguos). Me parece que ese es el sentido profundo de un curriculum vitae.

Este trabajo de Homenaje a Juan Antonio Estrada quiere ser también un reconocimiento, en el doble sentido de gratitud y de volver a poner de manifiesto, de su particular curriculum. Y no me refiero solo al académico, que es público y muy notable, sino a otro, que tiene que ver con algo más personal y que atañe a su actitud, a su talante, a su compromiso vital. Ni puedo arrogarme el derecho ni es este el lugar de resumir los caracteres que definen lo que podría llamarse su estilo vital, pero más de treinta años de amistad me dan cierto derecho a ofrecer mi punto de vista sobre algunas de sus notas más relevantes. Y hay muchas: la coherencia, la generosidad, el trabajo intelectual, la cultura sin arrogancia... Quisiera destacar una y referirla sin ambages y con precisión: la valentía.

Como colega en el Departamento de Filosofía en la Universidad de Granada, he tenido ocasión de comprobarla; también como espectadora en los conflictos (a veces amargos) con la jerarquía 
eclesiástica; y mucho más, cuando, justo después del asesinato de los jesuitas en El Salvador en 1989, se ofreció voluntariamente a ocupar uno de sus puestos, aunque ello conllevara la renuncia a una brillante carrera que acababa de comenzar en la Universidad de Granada. Afortunadamente pudo hacer lo primero sin tener que renunciar a lo segundo. Pero no me refiero a todo eso.

Desearía subrayar otro aspecto de esa valentía, que es precisamente el que da título a este trabajo. Me refiero a su valor para vivir en el límite, para habitar un terreno fronterizo que no es solo incómodo, sino que a veces es inhóspito. Vivir en la frontera es vivir peligrosamente, es habitar una tierra de nadie, donde uno es doblemente extraño, porque ni los de una parte ni los de la otra te reconocen como propio. Hay que estar curtido o estar dispuesto a curtirse para vivir en la intemperie: en ese terreno fronterizo donde incluso los asuntos sobre los que se trabaja y se reflexiona tienen también carácter de frontera.

\section{Las obsesiones de un teólogo y las preguntas de un filósofo}

No son las únicas y a lo mejor ni siquiera son las últimas, pero no cabe duda de que hay dos preguntas que resuenan con fuerza en casi todas las obras de Estrada: el problema del mal y el problema del sentido. Unidas ambas a dos personajes o referentes que son incómodos porque ponen en duda ciertas seguridades o al menos llevan al límite dos peligros respectivos para la teología y para la filosofía: el ateísmo y el nihilismo.

Entre la fe y el ateísmo, el personaje de Job representa un escándalo para el creyente. Es verdad que el final del libro que lleva su nombre es extrañamente esperanzador, pero, a pesar de todo, el dogmatismo queda herido de muerte.

Y en el caso de Nietzsche, al invocar una filosofía del "peligroso quizás", que trata de sortear los peligros del nihilismo una vez que se ha experimentado hasta el final, la seguridad ha quedado descartada para siempre.

Entre el dogma y la negación de Dios; entre la seguridad y la desesperación, Job y Nietzsche son referentes fronterizos que experimentan una importante pérdida y viven una profunda crisis de confianza. A esta última voy a referirme brevemente, antes de examinar los problemas señalados.

\section{Breve excursus sobre la confianza}

Puesto que hemos iniciado este escrito hablando de la valentía, conviene señalar también la relación de esta última con el miedo. A medio camino entre la temeridad y la cobardía, el valor, el ánimo, el coraje no existirían sin el miedo. Son formas de superación y de afrontarlo. Como dice Nietzsche, valor tiene el que conoce el miedo y supera el miedo (Nietzsche 1992: 384; KSA 4, 358. Sobre la temática, del miedo puede consultarse Hoyos 2016, y también Lord Moran 2018 y Marina 2013). Pero el miedo es una pasión compleja, relacionada con otras, con muchas y muy distintas, que constituye una fuente de interés para cualquiera que reflexione sobre la naturaleza humana. También está relacionado con la confianza, pero, antes de describir esa relación, quisiera advertir algunas cosas.

De acuerdo con Aristóteles, el miedo se asocia con la compasión en la tragedia (Poética: 1449b): se trata de las dos pasiones trágicas (Ávila 2018: 155 ss.), cuyo estudio desarrolla con amplitud Aristóteles en el libro II de la Retórica (1382a 20 ss. y 1385b 10 ss.).

Spinoza (Ética, III, pr. 18, sch. 2) lo asocia a la esperanza, conformando uno y otra el ámbito de las pasiones de la espera (sobre este punto véase Bodei 1995: 102-117), de las que, como buen racionalista, el pensador holandés pretendía alejarse y mantener a raya todo lo posible haciendo suyo el lema: Nec metu nec spe. He desarrollado todo esto en otra parte (Ávila 2018: 167 ss.), por lo que me dispenso ahora de prestarle más atención, pero sí quisiera insistir en la relación que ambas mantienen con el futuro y con la incertidumbre respecto a lo que acaecerá. Cuando el futuro deja de serlo y se hace presente, cuando ya no caben motivos de duda alguna, señala el pensador judío, la esperanza se transforma en seguridad, y el miedo, en desesperación (Ética, III, pr. 18, sch. 2).

Advierto esto, primero, porque creo que la confianza está relacionada con el miedo y, luego, porque creo 
también que a veces aquella se confunde con la esperanza. Y es preciso distinguirlas.

El Diccionario de la lengua española define la confianza como "esperanza firme que se tiene de alguien o de algo", también como "seguridad que alguien tiene en sí mismo" y como "ánimo, aliento, vigor para obrar". Es cierto que tiene que ver con la esperanza, pero el carácter inestable de esta última contrasta con la firmeza de la primera: "una esperanza firme". Confiamos en alguien cuando creemos que no nos decepcionará; cuando podemos predecir cómo actuará; y, en fin, cuando somos capaces de poner entre paréntesis, de suspender la incertidumbre respecto de su comportamiento. Esta capacidad de "predecir el futuro" tiene mucho que ver con aquel "animal que puede prometer", como define Nietzsche al hombre en el Segundo Tratado de La genealogía de la moral, con aquel animal al que le es lícito hacer promesas y que, al dar su palabra, honra al otro y se honra a sí mismo mediante una capacidad de control de futuro que no parece tener ninguna otra especie. Naturalmente esa confianza se puede traicionar o se puede afianzar dependiendo del modo en que el que hace promesas o el que es digno de confianza se comporte en el futuro. En todo caso, predicción y certidumbre parecen acompañar a la confianza y distinguirla de la pura y simple esperanza. A todo ello habría que añadir que no parece posible que la vida humana, o mejor, las relaciones humanas puedan prosperar sin ella.

Por otro lado, la confianza es una pasión relacionada con el miedo. Aristóteles habla de ella en el Libro Segundo de la Retórica, donde analiza 13 pasiones fundamentales y allí la opone al miedo. En el cap. 5 señala dos pasiones contrarias: el miedo y la confianza. A esta última se refiere en el segundo apartado.

Como siempre, Aristóteles la define primero; luego, se detiene en la consideración de lo que despierta confianza; y, finalmente, examina en qué disposición se encuentra quien la siente: "Una vez que ha quedado claro qué es el temor (...), se hace claro también qué es tener confianza, así como en relación a qué cosas y estando en qué estado de ánimo se es confiado" (Retórica, II, 1383a 15).

Conviene recordar cómo define Aristóteles el miedo: "un cierto pesar o turbación, nacidos de la imagen de que es inminente un mal destructivo o penoso" (Retórica, II, 1382a 20). Por el contrario, la confianza, que Aristóteles considera como "lo contrario del temor", es "una esperanza acompañada de fantasía sobre que las cosas que pueden salvarnos están próximas y, en cambio, no existen o están lejanas las que nos provocan temor". Se entiende ahora por qué hemos señalado antes que se trata de una "esperanza firme" y, en efecto, la firmeza se desprende de la idea (fantasía) de que los males que pueden aquejarnos no existen o están lejos, estando próximos los que pueden salvarnos.

Aristóteles añade que "da confianza el que las desgracias estén lejos y los medios de salvación cerca; el que existan remedios y se disponga de recursos (...), el no haber sido víctima de injusticia ni tampoco haberla cometido; el no tener, en general, antagonistas o el que estos no tengan capacidad de hacernos daño o, caso de que la tengan, sean amigos o nos hayan hecho algún beneficio o lo hayan recibido de nosotros y el que aquellos a quienes conviene lo mismo que a nosotros sean más numerosos o más poderosos o ambas cosas a la vez" (Retórica, II, 1383a 20-25).

Finalmente, Aristóteles advierte que son confiados "los que están a bien con los dioses tanto en las demás cosas como en lo que resulta de sus signos y preceptos: porque la ira hace a uno confiado, y el no cometer injusticia, sino padecerla, provoca ira, y se supone que la divinidad socorre a los que padecen injusticia" (Retórica, II, 1383b 5-10).

Creo que esta reflexión aristotélica es oportuna y nos permite afrontar un problema que considero central para este trabajo: la pérdida o crisis de confianza. Una pérdida que no es ajena para muchos a la ausencia de Dios; que está relacionada con su silencio o simplemente con su desaparición del horizonte de la reflexión. "La mayoría de edad del cristianismo arranca precisamente del silencio de Dios", escribe Estrada (1997: 390). Y este silencio resulta clamoroso en la mayor parte del libro que Job protagoniza. También Nietzsche previene contra una concepción de la vida a nuestra imagen y constata una pérdida de confianza que coincide con el inicio de sus obras de madurez. En este marco destacaremos los dos problemas apuntados más arriba: el problema del mal y el del sentido de la vida.

\section{El problema del mal y la imposibilidad de una teodicea}

Dice Estrada (1997: 17) en su excelente obra La imposible teodicea que el problema del mal es inseparable del problema del sentido y, por eso, por su conexión con el sentido de la vida, el mal es un 
problema de interés para la religión y para la teodicea. Pero la teodicea es también un puente entre la filosofía y la religión: es tanto una explicación como una defensa de Dios ante el problema del mal (Estrada 1997: 33).

Es curioso cómo se entrelazan aquí tantos problemas cruciales en la vida del hombre y cómo, una vez más, de acuerdo con lo que han señalado muchos pensadores, la religión y la filosofía, el mito y la razón, exhiben sus orígenes comunes.

Mal y sentido, dicho muy brevemente y sin matizaciones muy profundas de momento, podrían definirse por sus opuestos. El mal se opone al bien más que a la felicidad (aunque esta sea un tipo de bien) y por "bien" cabe entender lo que, como diría Spinoza (Ética IV, Def. I y II), tiende a nuestra propia realización, lo que expresa mejor nuestra naturaleza, lo que contribuye a nuestra propia utilidad: lo mejor de nosotros y lo más propio. Por su parte, "sentido" se opone a sinsentido y creo que Camus toca un tema crucial de la filosofía al elevar lo absurdo a una categoría filosófica fundamental. Pero de momento centrémonos en el primero: el problema del mal.

Estrada recoge la distinción clásica entre el mal metafísico (relacionado con la fugacidad de la vida y con la muerte), el mal físico (que se desprende del dolor y el sufrimiento) y el mal moral (unido a la libertad y a la responsabilidad humana) (Estrada 1997: 11-16). Es inevitable recordar aquí la reflexión de Freud, cuando en El malestar en la cultura advierte las causas que se oponen a la felicidad: unas proceden de fuera, de la naturaleza amenazante, "capaz de encarnizarse con nosotros con fuerzas destructoras y omnipotentes"; otras, de nosotros mismos, de nuestro cuerpo, condenado al envejecimiento, la enfermedad y la muerte; finalmente, señala las que se relacionan con la vida en sociedad, con las relaciones humanas, es decir, con la violencia y el daño que nos procuramos unos a otros. Estas últimas se perciben a menudo como las más insoportables, pues tendemos a creer (tal vez equivocadamente) que no escapan a nuestro control y serían evitables si nos lo propusiéramos (Freud 1982: 20). Y es fácil, reconocer aquí, aunque levemente alteradas, las tres formas del mal referidas en el anterior párrafo.

Como si todas las reflexiones racionales fueran insuficientes, a pesar de tanto y tanto esfuerzo por explicarlo y por conjurarlo, el mal parece resistirse al lenguaje de la racionalidad. Nietzsche, Freud, Marx, Camus... por referirse solo a algunos pensadores han considerado con profundidad este problema; pero sus consideraciones "no bastan", dice Estrada (1997: 41), parece como si no expresaran del todo la variedad y el número de vertientes y de aristas que tiene el problema. $Y$ en ayuda de esta expresividad vienen los mitos. Con una cierta voluntad de "racionalidad", pero también de dar la palabra al lenguaje intuitivo y a la imaginación, su lenguaje simbólico no puede ser superado ni reducido al conceptual: en ellos encuentra acogida un ámbito especial, el ámbito de lo sagrado, y su carácter simbólico hace del suyo un lenguaje cifrado que requiere una interpretación (Ávila 1991: 413 ss.).

Hay muchos mitos que refieren el problema del mal: etiológicos, trágicos, de la caída, adámico... A ellos se refiere Estrada en el cap. 1 de La imposible teodicea, pero quisiera detenerme en el modo en que lo aborda cuando estudia la figura de Job.

Son muchos los lugares en los que Estrada alude unas veces y otras estudia detenidamente esta figura, pero casi siempre destaca su dimensión trágica, la experiencia radical de la vida como desgarro. Y destaca también la imposibilidad de entender este libro bajo la óptica de la retribución y, sobre todo, la imposibilidad de juzgar. No hay condena ni absolución: "la imposible teodicea".

La riqueza y la complejidad de este libro y de su protagonista, que ha sido tratado tantas veces y por los más diversos autores, a los que hay que sumar la lectura de Estrada, no es preciso reseñarlas. Solo quiero poner de relieve algo que hace de su estudio un caso singular en la reflexión filosófica y religiosa. No hacía falta esperar a Schopenhauer para poner de relieve que aquella ecuación socrática, que suscribía la estrecha relación entre razón, virtud y felicidad, entra tantas veces en una profunda crisis y es más un desideratum que un reflejo del estado habitual de las cosas. Me refiero a la divergencia radical entre "ser, bien y sentido", que Estrada (1987: 83) apunta y que en el caso concreto de Job, se trata del dolor sin cuento de un inocente.

La rebelión de Job, su escándalo, tiene su base aquí. Arranca de la convicción de que un Dios bueno (por definición) no puede tolerar la injusticia. $Y$ es injusticia que el malvado transcurra sus días en sosiego y felicidad y, en cambio, el justo sea colmado de desdichas (1). Y entonces o bien se demoniza al sufriente señalando, como hacen los amigos de Job, que algo ha hecho mal para que se halle así (2); 
o bien, como hace el propio Job, se acaba por impugnar a Dios "ante la experiencia del mal como algo injustificable y desmesurado" (Estrada 1987: 81 ss.) (ㄱ). . En todo caso lo que parece evidente en ambos casos es la invocación de la tesis de la justicia como retribución, de la ecuación culpa-castigo, que tanto empeño puso Nietzsche en criticar. Y, en el caso de que Job tuviera razón al alegar respecto de sí mismo una conducta impecable, lo que tiene lugar en este caso es una profunda y radical crisis de confianza.

De este libro, El libro de Job, cabría decir lo que de Así habló Zaratustra dijo Nietzsche: ocupa un lugar "absolutamente aparte". La extrañeza, la belleza, la profundidad de este libro lo hacen único. Y quiero detenerme en este texto con el fin de poner de relieve un aspecto que va de la mano de esa "teodicea imposible" que defiende J. A. Estrada. En concreto, lo que deseo subrayar es el tránsito que experimenta el protagonista desde una vida apacible y confiada, donde todo está regulado según una idea de justicia retributiva y, sobre todo, donde Dios es previsible, hasta una experiencia tal de desorden y caos que dan la vuelta y trastocan su vida entera. En ese momento Dios parece dejar de estar de su lado y se convierte en alguien "imprevisible, difícil misterioso", como señala el introductor del libro a su edición castellana (Schöckel, p. 1323). De manera que esta obra sugiere una gran pérdida, una pérdida de la que dudo que, a pesar del "epílogo", pueda recuperarse Job jamás: la confianza. Vamos a recordar su contenido.

Al principio Job era feliz: a la prosperidad de que disfruta hay que añadir la observación por su parte de los preceptos divinos, el consejo y el consuelo a los amigos, el apoyo a los que tenían necesidad de él... Pero todo comienza a desmoronarse hasta que al final todo se derrumba. No siempre es la misma la respuesta de Job: primero, cuando pierde a todos sus hijos y sus propiedades, entonces Job "se rasgó el manto y se rapó la cabeza, se echó por tierra y dijo: Desnudo salí del vientre de mi madre/ y desnudo volveré a él. / El Señor me lo dio, el Señor me lo quitó, / bendito sea el nombre del Señor. / A pesar de todo, Job no protestó contra Dios" (Job, 1, 20-22).

Luego, cuando su cuerpo se convierte en una llaga purulenta y su mujer lo incita a la desesperación y a maldecir a Dios, todavía Job le replica: "Hablas como una necia. Si aceptamos de Dios los bienes, ¿no vamos a aceptar los males? / A pesar de todo Job no pecó con sus labios" (Job, 2, 10-11).

Finalmente, vienen a verle sus amigos para compartir su pena y consolarlo. Reconociéndolo apenas, rompen a llorar y "pasan siete días con sus noches" junto a él, "viendo lo atroz de su sufrimiento". Y es entonces cuando comienza un cambio radical y Job pierde su paciencia y apacibilidad.

$\mathrm{Ni}$ el Schopenhauer más inspirado podría entonar un canto contra la vida como el que entona Job en el cap. 3 de este libro, que comienza maldiciendo el día en que nació y termina añorando la muerte, tras describir un presente inhabitable. Pero la tensión dramática no ha hecho más que empezar y se acrecienta con el diálogo que tiene lugar entre sus amigos Elifaz de Temán, Bildad de Suj, Sofar de Naamat, por un lado, y el propio Job, por otro. Una vez más, los amigos inician cada cual un discurso que podría ser consolador si tuvieran razón, es decir, si Job hubiera cometido alguna falta y si lo que ahora sufre se explicase como el castigo de una culpa o la compensación de un delito. Alternativamente se suceden los argumentos de los amigos a favor de un Dios, que actúa con arreglo a la ley, y la autodefensa de Job, que no encuentra delito ni falta en su propia conducta. Y Job se desespera ante argumentos que de nada le sirven, ante la defensa de una justicia retributiva que contradice su propia experiencia: "Soy inocente; no me importa la vida, / desprecio la existencia; pero es lo mismo -os lo aseguro-: Dios acaba con inocentes y culpables" (Job, 9, 21-22). Hasta que Job termina impugnando la justicia que defienden sus amigos y pide a Dios que acuda a juicio y dé razones: "Que me pese Dios en la balanza sin trampa y comprobará mi honradez" (Job, 31, 6).

El dolor aviva las preguntas. Como decía Schopenhauer, no hay reflexión sin dolor. Pero, en este caso, el sufrimiento de Job alimenta más bien una duda profunda, una desconfianza sobre la identidad de un Dios, que ahora muestra un rostro desconocido y adopta una conducta inesperada y una actitud cruel.

Job protesta ante sus amigos y se defiende contra el malentendido de sus propias palabras: "¡Qué persuasivas son las palabras certeras!; / pero, ¿qué prueban vuestras pruebas? / ¿Pretendéis cogerme en mis palabras/ cuando lo que dice uno desesperado es viento? / Sería como sortearse un huérfano/ y tratar el precio de un amigo" (Job, 6, 23-27). Pero también dirige sus preguntas a una divinidad a la que invoca para que deje de torturar a alguien insignificante como él: “¿Qué es el hombre para que le des importancia, / para que te ocupes de él, / para que le pases revista por la mañana y lo examines a cada momento? (...). / Muy pronto me acostaré en el polvo, me buscarás y ya no existiré" (Job, 6, 17-21). 
A ella se dirige para implorar que deje de atormentarle y ante esa divinidad incomprensible, evoca un pasado cuyo recuerdo solo añade más dolor al dolor, pues, como dice Dante, no hay nada que produzca más dolor como el recuerdo de los días felices en un presente amargo. "Vivía yo tranquilo cuando me trituró, / me agarró por la nuca y me descuartizó, hizo de mí su blanco" (Job, 16, 12).

Y surgen las preguntas sobre el destino del hombre: ya no solo el porqué, sino también el para qué de la vida. "A dónde va el hombre cuando expira" "y tú destruyes las esperanza del hombre; / muerto el varón, ¿puede revivir?" (Job, 14, 10-19).

Pero no hay respuesta. Solo el silencio, Un silencio obstinado y en absoluto elocuente. Silencio y nada más. Ansioso de pleitear con Dios, de defender sus razones ante Él, dispuesto a discutir lealmente con Él y seguro de ganar definitivamente su causa, Job se desespera ante su ausencia: "Pero me dirijo al levante y no está allí; / al poniente, y no lo distingo; / lo busco al norte y no lo veo; me vuelvo al mediodía, y no lo encuentro" (Job, 23, 8-9). Y eso mismo ocurre con respecto al saber, a la aclaración de un mundo que ya no es nunca más familiar, sino extraño, inhóspito, siniestro. Y, sobre todo, incomprensible: "Pero la sabiduría, ¿de dónde se saca?, / ¿dónde está el yacimiento de la prudencia? / El hombre no sabe su precio, / no se encuentra en la tierra de los vivos. /Dice el Océano: 'No está en mí'; responde el Mar: 'No está conmigo" (Job, 28, 12-14).

Hay que llamar la atención sobre el hecho de que Job no duda en ningún momento de que Dios exista: duda por el contrario de poder encontrarlo y, desde luego, de su propia naturaleza, que se revela ahora tan opaca, tan misteriosa, tan imprevisible. Entonces, antes de que Dios mismo se descubra (o se vele, porque se trata también de un velamiento), tiene lugar un extraño discurso: el de Elihú, un joven que había acompañado a los amigos de Job y que hasta ahora había permanecido en silencio. Después de que los amigos de Job renunciaran a responderle, convencidos ya de su inocencia, entonces toma la palabra Elihú, "hijo de Baraquel, del clan de Ram, natural de Buz". Y manifiesta su indignación tanto respecto de Job, que pretendía tener razón contra Dios, como de sus amigos, que no hallan una respuesta adecuada y parecen dejar a Dios como culpable. Protesta contra Job, al que acusa de no tener razón y de atreverse a llamar a juicio a Dios, comparándose así con lo inconmesurable: "porque Dios es más grande que el hombre. / ¿Cómo te atreves a acusarlo de que no contesta a ninguna de tus razones? / Dios sabe hablar de un modo o de otro / y uno no lo advierte" (Job, 33, 12-14).

Es verdad que hay en este discurso un reconocimiento de la retribución, de la justicia de Dios (4 4$)$. Y en ese punto parece ofrecer apoyo a la tesis que este libro pone entre paréntesis. Pero a mi juicio la novedad de este discurso reside en dos cosas que resumen el acto IV y último del libro.

Me refiero, por una parte, a la imposibilidad de reducir lo infinito a lo finito, a la radical heterogeneidad entre el hombre y lo divino: “¿Te parece razonable lo que dices: / 'Llevo razón contra Dios'? / Añades: '¿De qué me ha servido, / qué he ganado con no pecar?' / Yo voy a responderte a ti / y a la vez a tus amigos. / Mira atentamente al cielo / y fíjate en las nubes tan altas. / Si pecas, ¿qué mal le haces a Dios? / Si acumulas los delitos, ¿qué daño le haces? / Si eres justo, ¿qué le das a él / o qué recibe de tu mano? / Es a un ser humano a quien afecta tu maldad; / a un hombre, como tú, su justicia" (Job, 35, 2-8). Es como si la distinción entre el bien y el mal fuese algo que solo atañe al hombre, a un plano ontológico inferior y distinto, y a no a la divinidad o al Todo, como diría Spinoza.

Por otra parte, esa radical heterogeneidad afecta a la imposibilidad de comprender, incluso, podríamos añadir, de nombrar. Adelantando el discurso que Dios dirige a Job, también Elihú le reprocha una ignorancia radical, un desconocimiento insalvable: "Escúchame esto, Job, / fíjate en las maravillas de Dios: / ¿Sabes cómo carga Dios las nubes, / maravilla de sabiduría consumada; / tú, que te abrasas en tu ropa / cuando la tierra se aletarga bajo el viento del sur? / ¿Puedes tender con él el firmamento, / duro como espejo de metal fundido?" (Job, 37, 14-18).

Y es entonces cuando Dios toma la palabra, hablando ahora a Job "desde la tormenta", prolongando y desarrollando lo que solo estaba en ciernes en el discurso anterior: "¿Quién es ése que denigra mis designios / con palabras sin sentido?/Si eres hombre, cíñete los lomos: / voy a interrogarte y tú responderás. / ¿Dónde estabas cuando cimenté la tierra? /Dímelo, si es que sabes tanto. / ¿Quién señaló sus dimensiones? -si lo sabes-, / ¿o quién le aplicó la cinta de medir? (...). / ¿Quién cerró el mar con una puerta / cuando salía impetuoso del seno materno, / cuando le puse nubes por mantillas/ y niebla por pañales, /cuando le impuse un límite / con puertas y cerrojos, / y le dije: 'Hasta aquí llegarás y no pasarás; laquí romperá la arrogancia de tus olas'? (...). /¿Puedes atar los lazos de las Pléyades / o 
desatar las ligaduras de Orión? /¿Puedes sacar las constelaciones a su hora /o guiar a la Osa con sus hijos? (...). / ¿Quiere el censor discutir con el Todopoderoso? (...). / ¿Te atreves a violar mi derecho / o a condenarme para salir tú absuelto?" (Job, 38-40).

Este discurso parece inspirar las reflexiones posteriores sobre lo santo, reflejando lo "tremendo y fascinante" del ámbito de lo sagrado y de lo numinoso. Dios replica a Job con un alegato que aparentemente no aclara demasiado y que parece eludir la cuestión de la justicia propuesta hasta ahora, pero que es más que todo eso y pone de relieve la imposibilidad de comprender y reducir. Más que una exhibición de fuerza y de poder, que lo es sin duda, encontramos aquí una aproximación a un concepto como el de lo sublime, donde se enfrentan elementos del todo desiguales; $y$, sobre todo, una presencia de lo incomprensible, de los que está más allá de los nombres: de lo sagrado.

Ambas cosas se ponen de relieve en la breve pero muy elocuente respuesta de Job: "Me siento pequeño, ¿qué replicaré? / Me taparé la boca con la mano" (Job, 40, 4). Y ya al final: "Reconozco que lo puedes todo / y ningún plan es irrealizable para ti / -yo, el que empañó tus designios con palabras sin sentido-; / hablé de grandezas que no entendía, / de maravillas que superan mi comprensión. / (...) Te conocía solo de oídas, / ahora te han visto mis ojos; / por eso me retracto y me arrepiento /echándome polvo y ceniza" (Job, 42, 2-6).

No importa que en el Epílogo, que constituye el "final feliz" de esta tragedia, Job aparezca de nuevo retribuido y reconocido, gozando de más prosperidad aún de la que gozaba al principio. No importa, porque, como advierte repetidamente Estrada, la felicidad de hoy no compensa el dolor de ayer. Pero, sobre todo, porque lo que este extraño libro manifiesta y lo sitúa en un lugar absolutamente aparte es una revelación de lo sagrado como extraño y hostil, como inhóspito e inquietante (cfr. Ávila 2010: 97 ss.). Las reflexiones de muchos pensadores actuales, entre los que hay que contar señaladamente a Heidegger, tendrían aquí una fuente de inspiración, porque este Dios de Job no es el Dios protector al que se acude para que favorezca y preserve de todos los peligros: es un Dios extraño. Extraño al hombre y a su mundo. $Y$ se parece a aquellas divinidades griegas que pueden favorecer o aniquilar, pero ante las cuales es preciso tener respeto y pudor y mantener un cierto alejamiento.

Es verdad, como dice una cierta Teología negativa, "los nombres no te nombran", pero tampoco el entendimiento te comprende, por eso, solo cabe formular preguntas, mantener bajo el signo de interrogación lo que apenas puede vislumbrarse. Y eso mismo, el preguntar, aquella "piedad del pensar" a la que se refirió Heidegger, es lo único que le está permitido al pensamiento ante la vecindad de lo sagrado. Eso es, una vez más, habitar la frontera.

En esa frontera ya no se vive en la propia casa, a menos que uno reconozca que el hogar, lo familiar, lo cercano es también lo inhóspito, lo siniestro, lo extraño. Es decir, aquel paraíso en el que alguna vez habitó el hombre es ahora, después de haber comido del árbol de la ciencia, un "paraíso perdido". Y la confianza, la seguridad y la certidumbre que alguna vez tuvimos son ahora inquietud, incertidumbre, inseguridad. Pero quizás en la frontera y en la intemperie, aunque no sea fácil, sea posible alguna vez vivir.

\section{El problema del sentido y la ambigüedad de las cosas últimas}

No es posible ninguna teodicea: si ciertamente Dios no puede ser acusado, tampoco puede ser absuelto. Eso es lo que parece enseñar la reflexión de Estrada y lo que puede desprenderse del acercamiento a este personaje. El mal sigue ahí y su relación con la divinidad es una incógnita que nunca puede despejarse del todo, o mejor, que no tiene respuesta definitiva. $Y$ a esa conclusión hay que añadir una segunda que acaba de apuntarse: la situación de incertidumbre, de ausencia de seguridad y de confianza.

Pero, además, con la pregunta que suscita el problema del mal, queda en pie otra, relacionada con él como se vio, que forma parte de él, que es uno de sus aspectos: la pregunta por el sentido, es decir, por el valor de la vida. En este punto es Nietzsche la gran referencia de las reflexiones de Estrada, abundantes en toda su obra, pero particularmente presentes en el cap. 5 de La imposible teodicea y en el cap. 4 de El sentido y el sinsentido de la vida. A ellas quiero referirme en lo que sigue.

Quizás para aclarar de qué hablamos cuando hablamos de sentido, conviene señalar que hay sentido 
cuando hay explicación, cuando algo tiene un porqué y un para qué. "Sentido" es dirección, orientación, trazado: se supone que se cuenta con él cuando alguien se dirige a un lugar y proviene de otro. Un paso más en esta aclaración tiene que ver con el término que se le opone: "absurdo". Con este término se designa lo que no tiene explicación ni sentido, lo que no tiene causa ni finalidad.

Creo que A. Camus, otro de los autores amados por Estrada, acierta plenamente en la definición de absurdo que ofrece en El mito de Sísifo, como el "divorcio entre el actor y el decorado" (Camus 1999: 16). Si nuestra vida fuese una representación en ese gran teatro que es el mundo, carece de sentido cuando no hay unidad ni lógica en la representación. Shakespeare (1981: 128) lo dijo mejor que nadie en el Acto V de las escena V de Macbeth: "La vida es una sombra tan solo que transcurre, un pobre actor que, orgulloso, consume su turno sobre el escenario para jamás volver a ser oído. Es una historia contada por un necio, lleno de ruido y furia, que nada significa".

Hay un mal añadido en esta experimentación de la vida como absurdo: si la irresolución del problema del mal genera desconfianza, la posibilidad de sinsentido nos avecina peligrosamente a la sinrazón y a la locura. Estrada lo advierte cuando, invocando a Nietzsche, pone de relieve que la ausencia de sentido es lo verdaderamente insoportable para el hombre, que el hombre acepta el dolor con tal de que a este le sea asociado un sentido y que lo verdaderamente insoportable es el dolor inútil (Estrada 1997: 281 ss. y 2010: 164-167).

No puede extrañar que Estrada se acerque insistentemente a Nietzsche, aunque eso no signifique que comparta sus conclusiones, pero es cierto que desarrolla una profunda "voluntad de escucha" que toda hermenéutica auténtica suscribe. Solo una defensa banal del cristianismo demonizaría a un autor que hizo de su crítica, de la crítica al cristianismo, uno de los motivos fundamentales de su pensamiento. Pero había en esa crítica, además del rechazo, un profundo reconocimiento.

Por un lado, Nietzsche (1986: 184-186) reconoce que los ideales ascéticos propuestos por el cristianismo se habían hecho cargo hasta el momento de una cuestión fundamental: la pregunta por el sentido del sufrimiento. $Y$ habían satisfecho su demanda de sentido de tal modo que no solo el sufriente, sino la humanidad misma quedaba a salvo de un "nihilismo suicida" que amenazaba con hacerla sucumbir.

Y Nietzsche reconoce también en esa "voluntad de sentido" muchos elementos dignos de respeto: en primer lugar, el aspecto positivo que tiene en sí misma la disciplina, un cierto ascetismo (Ávila 1986: 177). En segundo lugar, el reconocimiento del sacerdote ascético como un personaje heroico y afín a Zaratustra (Ávila 1986: 178) y también como artista (Nietzsche 1972: 84-85). Pero, sobre todo, hay un reconocimiento de la figura de Jesús, que es evidente en El Anticristo, frente a la figura de Pablo de Tarso, y que llama poderosamente la atención por lo contundente e inesperado en Más allá del bien y del mal (parág. 60, pp. 85-86):

"Amar al hombre por amor a Dios- ése ha sido hasta ahora el sentimiento más aristocrático y remoto a que han llegado los hombres. Que amar al hombre sin ninguna oculta intención santificadora es una estupidez y una brutalidad más, que la inclinación a ese amor al hombre ha de recibir su medida, su finura, su grano de sal y su partícula de ámbar de una inclinación superior: quienquiera que haya sido el hombre que por vez primera tuvo ese sentimiento y esa 'vivencia', y aunque acaso su lengua balbucease al intentar expresar semejante delicadeza, ¡continúe siendo para nosotros por todos los tiempos santo y digno de veneración, pues es el hombre que más alto ha volado hasta ahora y que se ha extraviado del modo más hermoso".

No es este el lugar para profundizar en los juicios de Nietzsche, pero sí para justificar que el problema del sentido, al que Estrada dedica una de sus obras señaladas antes, haga de Nietzsche un valiosísimo interlocutor al que toma muy en serio. Como también Nietzsche tomó muy en serio esa temática, aunque obviamente él y Estrada transitan por caminos muy distintos y, antes de señalar sus diferencias, quiero advertir algunas cosas a propósito de la respuesta que Nietzsche da al problema.

Creo que tanto Estrada como Nietzsche llevan a cabo una profunda reflexión sobre un estado inicial de incertidumbre y de desconfianza. Por su parte, Nietzsche apunta algunas cosas esenciales que se aprenden después de una experiencia radical y que él denomina resumidamente "enfermedad". Si Estrada señala agudamente que "el silencio de Dios" es el punto de arranque de "la mayoría de edad del cristianismo" (Estrada 1997: 390), de un modo análogo advierte Nietzsche (en La gaya ciencia, prólogo a la segunda edición, parág. 3, p. 720) que, tras aquella experiencia, "se acabó la confianza en la vida": "La 
confianza en la vida ha desaparecido. La vida misma se ha convertido en problema. ¡Que no se crea, sin embargo, que con esto uno se vuelve necesariamente sombrío! Incluso el amor por la vida es todavía posible, solo que se ama de otra manera. Es el amor por una mujer que nos crea dudas...". Pero las cosas no acaban ahí.

El problema del sentido, de la dirección y el valor de la vida se hace más acuciante tras el estado de inseguridad e incertidumbre. Y la posibilidad de absurdo y sinsentido no puede despacharse sin más, pues lo que está amenazado es tanto la lógica y la razón (con la posibilidad de la locura) como la vida misma (la posibilidad del "nihilismo suicida" referido). Con una coherencia fuera de toda duda, Nietzsche desplaza el problema, lo resitúa y lo coloca en el lugar que estima adecuado. Por más antikantiano que se confesara, ahora, en un movimiento cercano al Kant de la Primera Crítica, donde este último advertía que lo que era válido para el fenómeno no podía extrapolarse al ámbito del noúmeno, también Nietzsche lleva a cabo su propio "giro copernicano" y su particular revolución. También está el silencio cuando se trata de averiguar "las cosas últimas": el valor de la vida, el sentido de la existencia.

Nietzsche no abandona el problema del sentido, reconoce que, tomado como algo radical (es decir, como algo válido para todos y que hace referencia a la vida en general, tomada como un todo), se trata de un problema demasiado grande para nosotros. Pero lo retoma y lo coloca en el lugar que, según él, le corresponde: en el ámbito de la vida de cada uno, en el ensayo que debe ser la existencia de cada hombre que se propone dar un sentido a la suya: "Este es mi camino, ¿dónde está el vuestro? Así respondía yo a los que me preguntaban 'por el camino'. ¡El camino en efecto no existe!" (Nietzsche 1992: 272).

Como he advertido en otra parte (Ávila 1999: 200-201), tocamos aquí una cuestión de primer orden, que revela lo que en la reflexión de Nietzsche hay de "trascendental", en el doble sentido -usual y filosóficodel término. Lo último en Nietzsche, aquello que es condición de posibilidad de todo lo demás, aquello más allá de lo cual no se puede ir, es la vida. Su valor no puede ser discutido, ni demostrado, ni tasado:

"Los juicios de valor sobre la vida, en favor o en contra, no pueden, en definitiva, ser verdaderos nunca: únicamente tienen valor como síntomas, únicamente importan como síntomas, en sí tales juicios son estupideces. Hay que alargar del todo los dedos hacia ella y hacer el intento de agarrar esta sorprendente finesse [finura], que el valor de la vida no puede ser tasado. No por un viviente, porque este es parte, más aún, incluso objeto de litigio, y no juez; no por un muerto, por una razón distinta. El que por parte de un filósofo se vea un problema en el valor de la vida no deja de ser, pues, incluso un reparo contra él, un signo de interrogación puesto junto a su sabiduría, una falta de sabiduría" (Nietzsche 1975: 38).

La vida es el horizonte y el marco de todos los valores, pero ella misma está más allá del bien y del mal. Es el dato inmediato, lo absolutamente dado, y aun en aquéllos que ponen su valor en entredicho acaba por hacerse patente al fin lo que ella es: voluntad de poder. Por extraño que parezca Nietzsche emplea aquí un razonamiento análogo al que sostiene Aristóteles en el libro IV de la Metafísica a propósito de la validez del principio de no contradicción. Aristóteles defendía allí su absoluta vigencia, manteniendo al mismo tiempo que un principio así no podría demostrarse sin cometer petitio principii. En efecto, si toda demostración supone el uso del principio, intentar una demostración del principio mismo sería caer en un círculo. Todo lo que puede hacerse es probar su vigencia refutando a aquéllos que niegan su validez. Aristóteles instaura el principio via refutationis. Y termina señalando que la proposición que lo enuncia no puede considerarse una proposición entre otras, sino la condición misma de posibilidad de todo discurso.

Pues bien, volviendo a nuestra temática, hay que reconocer que hay algo ambiguo, extraño, desconocido en estas cosas últimas, que son Dios para Job, o la Vida para Nietzsche... Hay algo "fascinante y tremendo", que hemos señalado a propósito del Dios de Job y que Nietzsche refiere a la Vida en "La canción del baile" de su Zaratustra. Algo inapresable, irreductible, "insondable" en esas cosas últimas (Nietzsche 1992: 163).

Y habría que señalar que lo que apunta Estrada (1997: 342 y 2010: 22 y 188 ss.) a propósito de Nietzsche en el balance que hace de su pensamiento -la radicalidad de las preguntas y la fragilidad de las respuesta-, eso mismo habría que hacerlo extensible si no a la religión, al ámbito extremo de lo sagrado, que desde cualquier ámbito -ateo o teísta- cabe defender.

A la imposibilidad de una teodicea, que Estrada (1997: 294-304) argumenta de manera impecable, tiene 
que seguir la imposibilidad de responder a las preguntas más radicales y, en fin, el reconocimiento del valor del misterio, del que él mismo se hace cargo más de una vez (Estrada 1997: 335-341). En este punto Estrada (1997: 327-332) nos invita a considerar otra salida y a otro autor que, partiendo del absurdo, ofrece una salida y un sentido cercano a Nietzsche, pero también distinto. Se apunta en este caso a A. Camus y a su interpretación humanista del teísmo cristiano.

\section{Pensar, creer, vivir... sin una teodicea}

El silencio de Dios, la imposibilidad de un juicio (de acusar o de absolver), su naturaleza opaca al conocimiento... Todo eso sitúa al creyente ante un serio problema. La antigua confianza, la reducción de la naturaleza divina a los parámetros y a las categorías humanas, es imposible. La imprevisibilidad, enemiga de la predicción, que acompaña a toda confianza, es un hecho innegable. Eso cabe aprender de la figura de Job.

Y con Nietzsche se pone de relieve que el problema del sentido, el del valor de la vida como un todo, no cabe plantearlo: es un problema que excede nuestros límites. Aquí no es solo el silencio, sino el anuncio de la muerte de Dios, el que parece conducir al pensador a un paisaje árido, a la intemperie.

En uno y otro caso la pérdida de confianza deja paso al desierto y a la soledad. Lejos de la tierra segura, a un paso del abismo, uno y otro enseñan a vivir en la frontera. De alguna manera eso es también lo que el examen detenido de estos y otros hitos de la reflexión de Estrada nos muestra. Entre esos hitos cabe advertir a dos pensadores que han sido especialmente relevantes para él: Adorno y Horkheimer. Pero hay, además de ellos y entre otros muchos, un pensador fronterizo también al que Estrada concede una atención especial, que parece revelarnos algo de su propio compromiso como pensador y al que quiero por lo menos aludir. Me refiero a A. Camus.

También Camus parte de una posición "desencantada", insegura, lejos del horizonte confiado que hacía habitable la existencia. Pero no ha perdido el gusto por la vida: el encanto del amor y la amistad, el paisaje de la infancia con un mar abierto y un cielo azul, el gusto por las pequeñas grandes cosas que alientan la vida y que no necesitan porqué ni para qué. Con el trasfondo de aquella convicción trágica, A. Camus muestra también su particular modo de vivir en la frontera.

Rieux, el médico protagonista de La peste renuncia a la esperanza, pero no se resigna a la inacción. Curar, sanar, aliviar, calmar... ese es el compromiso de un hombre que, como el propio Camus señaló en su discurso a propósito de la concesión del Premio Nobel de Literatura, trata de "impedir que el mundo se deshaga". El héroe trágico es ahora un Prometeo que habita entre la gente y que apenas se hace notar, pero su trabajo, menos visible, menos expuesto al público (sobre todo, menos romántico), es, si cabe, todavía más eficaz. La pérdida de confianza en que el mundo tenga un sentido y en que esté sometido a la justicia; la ausencia incluso de esperanza, porque el bacilo de la peste, aunque se venza ocasionalmente, revivirá una y otra vez; la convicción del sinsentido del dolor... Todo eso no apaga, antes al contrario, reaviva un fuego de rebelión alimentado por el amor no ya a la humanidad, sino a los hombres concretos. Todo eso alienta la solidaridad, único alivio eficaz de la soledad. Y esa rebelión se concreta en la práctica, en la acción.

En una reflexión que deja entrever sus propias convicciones (y hasta buena parte de su personalidad), Estrada (1997: 323 ss.) muestra a Camus como una alternativa valiosa frente a Kant a Nietzsche y afirma su dimensión trágica: es imposible la teodicea, como es también imposible el sueño de curar y luchar para erradicar definitivamente el dolor y la muerte. Tampoco es posible la antropodicea, ni el hombre puede tomar sobre sí una responsabilidad que supera sus posibilidades. Es cierto que, en el balance que hace Estrada, después de su brillante exposición de A. Camus, señala que no es asumible ni puede mantenerse de continuo la rebelión promovida por Camus, pero también reconoce en él una posición perfectamente defendible y, sobre todo, que "la solución teísta no tiene el monopolio de la generosidad y de la compasión respecto de las víctimas" (Estrada 1997: 326).

En ese sentido apunta Estrada (1997: 327) a Bloch como un paso más en la búsqueda de otros modos de habitar la frontera: "una interpretación humanista del teísmo cristiano". Bloch opone la esperanza, ese principio que da título a su obra más conocida, al absurdo y a la dimensión trágica. Y Estrada considera su postura un "cristianismo ateo". La reflexión de Bloch, como la de Camus, sostiene y defiende una 
actitud pragmática en la que razón y sentimiento están igualmente implicados. De la mano de estos pensadores concluye Estrada de nuevo la inconsistencia de cualquier teodicea, pero también la insuficiencia de la antropodicea. Y desde aquí se va dibujando su propia posición como teólogo y como pensador.

Nietzsche, Marx, Freud, Camus... son propuestas alternativas que, de acuerdo con lo que advierte al inicio de La imposible teodicea, "no bastan" (Estrada 1997: 41). Al final de esta obra se concluye que todo intento de justificación, de explicación, o de defensa de Dios frente al mal es un esfuerzo inútil. Pero, como sucede en Kant a propósito de la metafísica entendida como formulación de preguntas últimas y fundamentales, también estas preguntas tienen el doble carácter de inevitabilidad y de imposibilidad. Y eso tiene otra cara: si Epicuro tiene razón al criticar la bondad y la omnipotencia de los dioses frente a la experiencia insistente del mal, también cabría la pregunta de Boecio: ¿Por qué el mal, si Dios existe? ¿Por qué el bien si no existe Dios? (Estrada 1997: 343).

Una vez más el teísta y el ateo se ven confrontados y tal vez incluso condenados a entenderse, pero conviene señalar sus límites. Uno y otro recurren siempre a un sistema o a una escala de valores: el más radical en esto, F. Nietzsche, afirmaba sin ambages que no se puede vivir sin valorar (Nietzsche 1992: 96). El problema está en dónde asentar dicha escala. Y Estrada (1997: 344) advierte agudamente las reservas que cada cual esgrime contra el otro: "siempre queda al teísta la posibilidad de preguntar al ateo en qué basa su esperanza de mantener la obligatoriedad de esos valores". Pero también ocurre al contrario: "la fragilidad de la opción atea en la lucha contra el mal también se vuelve contra el teísta: ¿en función de qué espera persistir en esos valores y esa fe, a pesar de que son contrafácticas y constantemente desmentidas por la historia? ¿Cuántas experiencias de mal puede soportar sin cuestionar su fe en un Dios omnipotente y bueno?" (Estrada 1997: 345). Estrada reconoce que hay valor y grandeza en los que rechazan la existencia de un Dios creador de un mundo que contiene tanto mal: el agnóstico y el ateo, advierte Estrada (1997: 345), "asumen la soledad del protagonismo humano". Y, en todo caso, "las preguntas que suscita el mal se vuelven tanto contra el humanismo ateo como el religioso". La conclusión no se deja esperar: la imposibilidad de una teodicea abre paso a una profunda crisis: la confianza, la seguridad no va más allá de un sueño infantil , y su abandono, el abandono de la certidumbre, supone la entrada en una mayoría de edad y la decisión de habitar el peligroso espacio de la frontera. Y en eso, como Estrada (1997: 391 y 2010: 180-188) reconoce, ambos están unidos: "el ateísmo es el compañero inseparable del teísmo cristiano".

Nuestra reflexión podría acabar aquí. El filósofo y el teólogo, aun reconociendo palpables diferencias, habitan un terreno común. Y esa doble dimensión, que es también conflicto entre los dos y en cada uno, se deja ver en la reflexión de Estrada con una honestidad y una coherencia notables. Pero la reflexión quedaría incompleta si, atendiendo al pensar y al creer, dejáramos fuera la vida, el compromiso de quien es algo más que un pensador, en su doble dimensión de filósofo y teólogo. Solo la apuntaré, pero esa apuesta y ese compromiso no pueden ser silenciados.

En el capítulo 7 de La imposible teodicea, que lleva como título "La implicación cristiana en la lucha contra el mal" encontramos una posición personal que completa este libro problemático y difícil, en el que no se han pasado por alto dificultades ni terrenos movedizos. No detallaré el compromiso que Estrada explicita con el cristianismo y en concreto con la figura de Jesús, pero es preciso subrayar que la opción que hace suya prolonga aquella ya apuntada a propósito de A. Camus en que la rebelión se hacía carne en la acción, en la praxis. Una praxis que, en este caso, se sitúa en las proximidades de la llamada "teología de la liberación" y en general en la opción por las víctimas.

De esta opción forma parte una interpretación personalísima de la espinosa problemática de la resurrección y de la inmortalidad (Estrada 1997: 372 ss.), pero me interesa sobre todo subrayar el modo como afronta ahora el problema del dolor y el sufrimiento en unas páginas que llevan esta problemática en la que hemos centrado nuestro trabajo a su punto culminante. Estrada se sitúa a igual distancia de los extremos con que nuestro tiempo hace frente al problema: la dramatización del dolor o su banalización (ya Nietzsche denunció el malentendido del sufrimiento por parte del Romanticismo) (Mitchell 2013: 946 ss.); lejos de ambos extremos y lejos también de aquellas posiciones que pretenden "gestionar" las cosas últimas y más fundamentales y que constituyen tal vez el ámbito de lo más sagrado para el hombre, Estrada vuelve a tomar sobre sí este problema con un estilo claro, sobrio y sin ilusiones.

Más allá de un ansiado "final feliz", se mantiene el mysterium iniquitatis como algo irresoluble, incluso "en la propuesta de redención final hay siempre un elemento de tristeza, de luto y de negatividad irreparable" 
(Estrada 1997: 384). Es justamente entonces es también cuando se ha perdido la confianza, cuando la certidumbre y la seguridad de una tierra firme siguen ausentes; entonces también se hace presente la luz tenue de una esperanza, siempre amenazada, siempre incierta: la esperanza en que el amor sea más fuerte que la razón" (Estrada 1997: 393), en que la injusticia no tenga la última palabra. Pero para eso se precisa también una intensa experiencia del sufrimiento: no solo de oídas, sino una vivencia del mismo.

Eso es lo que Estrada destaca a propósito de la figura de Jesús. Lo que advierte como algo en igual medida novedoso y convincente es precisamente su enseñanza en la esfera práctica del dolor. En unas páginas de innegable inspiración, Estrada advierte el significado de la figura histórica de Jesús y adopta una cierta "hermenéutica de la cruz", que le lleva a afirmar que con él el rostro de Dios se esconde tras la víctima del mal y entonces ocurre "el milagro de encontrar a Dios donde nadie lo espera" (Estrada 1997: 394; véase también Estrada 2015: 176 ss.).

Uno podría pensar con Nietzsche que hay una extraña distorsión de la divinidad en este contexto y tal vez no le falte razón. Pero también podría concluir con O. Wilde (2012: 88) que "allí donde hay dolor hay un lugar sagrado". Y este ámbito de lo sagrado está sin duda más allá del ateísmo y de la religión.

\section{Notas}

1. “¿Por qué siguen vivos los malvados / y al envejecer se hacen más ricos? (...) / ¿Por qué no se lo preguntáis a los que han viajado / Y no creéis sus historias maravillosas? / Que en la catástrofe se salva el malvado/ Y que el día trágico lo encuentra ausente (...) / ¿Y me queréis consolar con vaciedades? / Vuestras respuestas son puro engaño" (Job, 21, 2-34).

2. "Tú que a tantos instruías / y fortalecías los brazos inertes, / que con tus palabras levantabas al que tropezaba/ y sostenías las rodillas que se doblaban, / ahora, que te toca a ti, ¿no aguantas?, / ¿te turbas hoy que todo te cae encima? / ¿No era la religión tu confianza / Y una vida honrada tu esperanza? / ¿Recuerdas un inocente que haya perecido?, / ¿dónde se ha visto un justo exterminado?" (Job, 4, 3-7). "Vuelves contra Dios tu furor, / Soltando protestas por la boca. / ¿Cómo puede el hombre ser puro / O inocente el nacido de mujer? / Ni aún a sus ángeles los encuentra fieles / Ni el cielo es puro a sus ojos; / ¡cuánto menos el hombre detestable y corrompido, / Que bebe como agua la iniquidad!” (Job, 15, 13-16).

3. "Todo eso lo han visto mis ojos, / Lo han oído mis oídos, y lo comprendo; / Lo que sabéis vosotros yo también lo sé, / Y no soy menos que vosotros. / Pero quiero dirigirme al Todopoderoso; / deseo discutir con Dios" (Job, 13, 1-3).

4. "Dios paga al hombre por sus obras, / lo retribuye según su conducta; / ciertamente Dios no obra mal" (Job, 34, 11-12). O cuando advierte: "Dios es poderoso / y no desprecia el corazón sincero, / no deja con vida al malvado, / hace justicia al pobre, no aparta sus ojos de los justos" (Job, 36, 5-7).

\section{Bibliografía}

Alonso Schökel, Luis

1975 Introducción a "El libro de Job”. Nueva Biblia Española. Madrid, Ed. Cristiandad.

\section{Aristóteles}

1999 Retórica. Madrid, Gredos. Trad. y notas de Q. Racionero

2011 Poética. Madrid. Intr., trad. y notas de T. Martínez Manzano y L. Rodríguez Duplá.

Ávila Crespo, Remedios

1986 Nietzsche y la redención del azar. Granada, Universidad de Granada.

1991 “El ocaso de los ídolos y la aurora de los símbolos”, en T. Calvo y R. Ávila (ed.), Paul Ricoeur: Los caminos de la interpretación. Barcelona, Anthropos.

1999 Identidad y tragedia. Barcelona, Crítica.

2010 "Lo inhóspito y lo sagrado", en P. Peñalver y J. L. Villacañas (ed.), Razón de Occidente. Madrid, 
Biblioteca Nueva.

2018 Las pasiones trágicas. Madrid, Trotta.

Bodei, Remo

1995 Una geometría de las pasiones. México D. F., Fondo de Cultura Económica.

Camus, Albert

1968 La peste. Trad. R. Chacel. Buenos Aires, Sur.

1981 Discurso concesión del Premio Nobel, 10 de diciembre de 1957. Madrid, Aguilar.

1999 El mito de Sísifo. Madrid, Alianza.

Estrada, Juan Antonio

1997 La imposible teodicea. Madrid, Trotta.

2010 El sentido y el sinsentido de la vida. Madrid, Trotta.

2015 ¿Qué decimos cuando hablamos de Dios? Madrid, Trotta.

Freud, Sigmund

1982, El malestar en la cultura. Madrid, Alianza.

Habermas, Jürgen

1984 Perfiles filosófico-políticos. Madrid, Taurus.

Hoyos Sánchez, Inmaculada

2016 Sobre el amor y el miedo. Madrid, Avarigani.

Job. Madrid, Ed. Cristiandad, 1975. (Edición de la Nueva Biblia española; traducción de L. Alonso

Schöckel y de J. L. Ojeda, con la colaboración de J. Mendoza de la Mora).

Lewis, Clive Staples

1989 Cautivado por la alegría. Historia de mi conversión. Madrid, Ed. Encuentro.

Lord Mora

2018 Anatomía del valor. Madrid, Arzalia.

Marina, José Antonio

2013 Anatomía del miedo. Barcelona, Anagrama.

Mitchell, David

2013 "How the free spirit became free: Sickness and Romanticism in Nietzsche's 1886 Prefaces", British Journal for the History of Philosophy, vol. 21, $\mathrm{n}^{\circ}$ 5: 946-966. http//dx.doi.org/10. 1080/09608788.2013.805.397

Nietzsche, Friedrich

1858-1889 Nietzsches Kritische Studienausgabe. Herausgegeben von G. Colli und M. Montinari. Walter de Gruyter. Berlín, 1967-1988 (KSA).

1972 Más allá del bien y del mal. Madrid, Alianza.

1975 Crepúsculo de los ídolos. Madrid, Alianza.

1986 La genealogía de la moral. Madrid, Alianza.

1992 Así habló Zaratustra. Madrid, Alianza.

2014 La gaya ciencia. Madrid, Tecnos.

Shakespeare, Williams

1981 Macbeth. Madrid, Alianza.

Spinoza, Baruch

1980 Opera, hg. Von C. Gebhardt, Carl Winters Universitätsbuchhandlung, Heidelberg, s. a. [1925], 4 vols. rist. 1972. Madrid, Editora Nacional.

Wilde, Oscar

2012 De profundis. Madrid, Siruela. 
